\title{
Optical Coherence Tomography Imaging: Novel Insights into the Vascular Response After Coronary Stent Implantation
}

\author{
Milosz Jaguszewski • Ulf Landmesser
}

Published online: 5 May 2012

(C) The Author(s) 2012. This article is published with open access at Springerlink.com

\begin{abstract}
Optical coherence tomography (OCT) is a highresolution imaging technique that is increasingly used for intracoronary imaging to characterize coronary atherosclerotic plaques and vascular responses after coronary stent implantation. Introduction of optical frequency-domain imaging (OFDI; second generation OCT) has simplified practical use of this novel imaging modality resulting in a more widespread availability in interventional cardiology. Here we highlight recent insights into the acute and chronic vascular response after coronary stent implantation by OCT imaging. OCT provides cross-sectional images with approximately 10 -fold higher resolution as compared to intravascular-ultrasound (IVUS), allowing for precise evaluation of tissue coverage and malapposition of coronary stent struts. More than 30 studies using OCT to compare vascular responses to different stents have now been reported. Recent studies have examined the relation between OCT-image characteristics and tissue composition around stent struts. OCT is used for evaluation of novel stent concepts, such as bioengineered stents and bioabsorbable stents, where it provides more accurate information than IVUS. While intracoronary OCT imaging is further developed, including faster 3D-OCT-image-reconstruction, larger OCT studies/registries with standardized analysis will provide more insights into clinical implications of observations from OCT-imaging after coronary stent implantation.
\end{abstract}

Keywords Optical coherence tomography - Optical frequency domain imaging - Stent . Coronary intervention . Stent thrombosis $\cdot$ Intravascular imaging

M. Jaguszewski $\cdot$ U. Landmesser $(\triangle)$

Cardiology, Cardiovascular Center, University Hospital of Zurich, Raemistrassse 100,

8091 Zurich, Switzerland

e-mail: Ulf.Landmesser@usz.ch

\section{Introduction}

Optical coherence tomography (OCT) is a near-infrared light-based imaging modality [1] that is now quite widely available in interventional cardiology. OCT provides highresolution cross-sectional images of the inner vascular wall and surface of blood vessels with an approximately 10-fold higher image resolution as compared to intravascular ultrasound (IVUS) [1]. OCT imaging uses an interferometry technique based on time-delay measurements of the light reflected or backscattered from the tissues [1]. There are two processing modes used for intracoronary OCT imaging, i.e. the first generation time-domain OCT imaging systems and the more recently available second generation frequencydomain OCT imaging systems, also called optical frequency domain imaging (OFDI) [2,3]. OFDI has made the application of OCT in the clinical setting substantially easier, in particular the faster image acquisition as compared to the first-generation time-domain OCT imaging systems $[4,5]$. Time-domain OCT and more recently OFDI have been used to analyze the vascular response to coronary stenting in a substantial number of studies, and the present article will summarize important insights from these investigations.

\section{OCT and Evaluation of Coronary Stent Healing: Focus on Stent Strut Coverage and Strut Malapposition}

While first generation drug-eluting stents reduced the need for repeated revascularization, coronary stent healing was also delayed, requiring prolonged double anti-platelet therapy in these patients $[6,7]$. Impaired coronary stent healing, in particular the lack of stent endothelialization, has been suggested as one important mechanism causing very late stent thrombosis in patients receiving a first-generation 
drug-eluting stent (Cypher and Taxus) as suggested by pathological studies $[8 \bullet]$. Several autopsy studies have described a markedly impaired neointimal healing of stent struts in patients who had a fatal late or very late coronary stent thrombosis $[9,10]$. Delayed healing was observed in patients after sirolimus and paclitaxel-eluting first-generation stent implantation as compared to BMS implantation as evident by persistent fibrin deposition and substantially impaired stent endothelialization $[9,10]$.

Intravascular ultrasound examination could not detect a thin neointimal coverage in the majority of sirolimus-eluting stent struts in the chronic phase raising the question to what extent these stents indeed remained uncovered [11]. OCT imaging clearly provided a substantially more detailed evaluation of coronary stent strut coverage as compared to the IVUS analysis [11] (Fig. 1.). In an early study of 34 patients who underwent coronary time-domain OCT and IVUS evaluation 6-month after sirolimus-eluting stent implantation the prevalence of covered stent struts as detected by OCT but undetectable by IVUS was $64 \%$ [11]. Therefore, there has been a great interest in the use of OCT for the assessment of the vascular response after coronary stent implantation.

Moreover, intravascular ultrasound (IVUS) studies have previously suggested a high prevalence of incomplete stent apposition (ISA) in patients with very late stent thrombosis after DES implantation [12, 13]. A meta-analysis of IVUS studies who had a baseline exam and a follow-up exam has indicated that the risk of late acquired stent malapposition is substantially increased after DES implantation as compared to BMS implantation, and late stent malapposition was associated with late and very late stent thrombosis $[12,13]$.

Due to the high resolution for the identification of coronary stent struts, OCT is likely capable to determine the apposition and degree of malapposition of stents struts in more detail (Fig. 2.). In a study using both, IVUS and OCT, OCT was superior in detection of malapposition of stent struts, likely due to its ability to detect small gaps between stent struts and the vessel wall that may be missed by IVUS
[14]. The stent strut is considered malapposed by OCT when the abluminal strut surface is separated from the luminal contour $[15 \cdot \bullet]$.

Importantly, OCT provides valuable insights providing a potential explanation for the relation between stent malapposition and stent thrombosis. In patients who had undergone first-generation sirolimus-eluting stent implantation it was observed that incomplete stent strut apposition (ISA) was associated with a substantially higher rate of impaired stent healing and with the presence of OCT-detected small thrombi at follow-up, further suggesting that stent strut malapposition and subsequently impaired stent healing represents a substrate for late or very late stent thrombosis [14]. Moreover, another study using OCT in 178 patients at 9 to 13 months follow-up after implantation of different drugeluting stents supported the notion that a delayed stent strut coverage was substantially more frequently observed (approximately 9-fold) in struts with incomplete stent strut apposition or in non-apposed side-branch stent struts [16]. Gutiérrez-Chico et al. have performed a study examining the relation between acute stent strut malapposition as detected and quantified by OCT and stent strut coverage in the follow-up exams at 6 to 13 months (including analysis of 66 stents) [17]. It was observed that the larger the initial stent strut malapposition the greater the likelihood of a delayed healing in the follow-up [17]. Interestingly, stent struts with small degrees of acute malapposition $(<270 \mu \mathrm{m})$ were covered and apposed in the follow-up exam [17].

As described in detail below, several studies have now compared stent strut coverage and strut malapposition for several types of coronary stents (i.e. DES and BMS), different DES at different time points after implantation, and for different clinical indications (i.e. stable CAD vs ACS) by using coronary OCT imaging. However, it needs also to be taken into account, as described in more detail below, that besides the characteristics and design of the stent, the stent implantation technique and the underlying clinical scenario requiring stent implantation (i.e. ACS with thrombotic
Fig. 1 The high resolution of OCT (axial resolution 10$15 \mu \mathrm{m}$ ) allows for detection of thin layers of stent strut coverage and sensitive detection of stent strut apposition/malapposition: a, OCT cross-sectional image demonstrating well apposed stent struts; b, OCT image demonstrating stent struts covered with a thin neointima layer that is below the IVUS axial resolution $(100 \mu \mathrm{m})$. Asterisk indicates OCT catheter. ST, stent strut
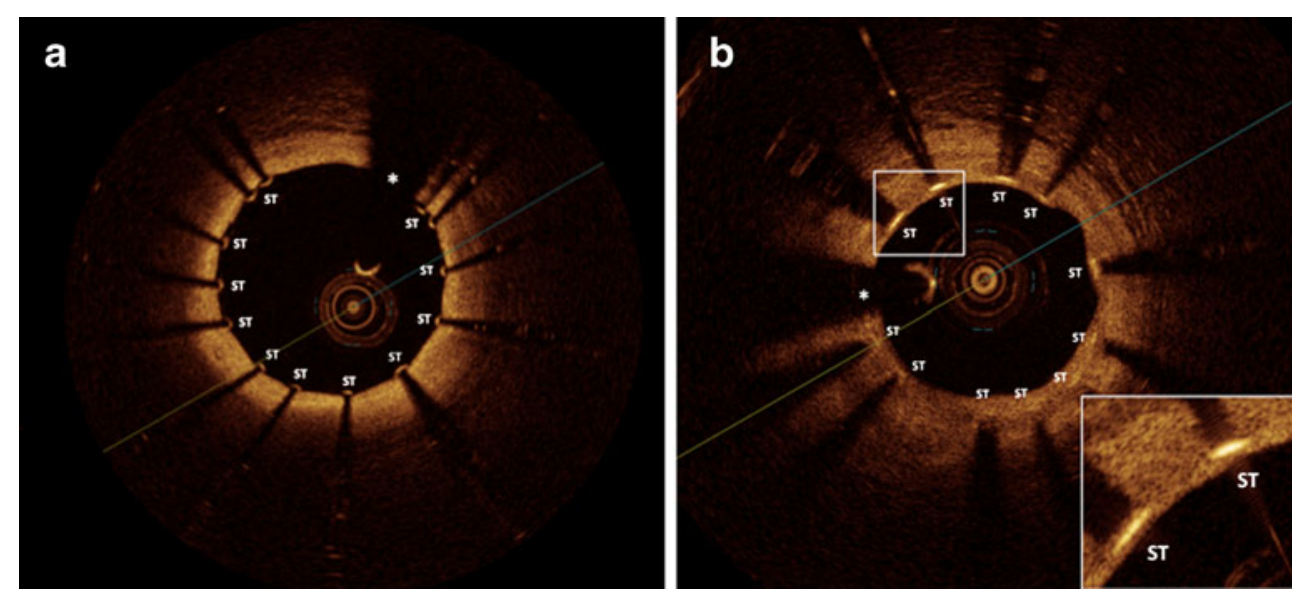
Fig. 2 Very late in-stent thrombosis after DES implantation. a, malapposed stent struts, that are at least partially uncovered (red arrows); $\mathbf{b}$, magnification of malapposed stent struts at least partially uncovered or covered by protruding white thrombi. Asterisk indicates OCT catheter. ST, stent strut
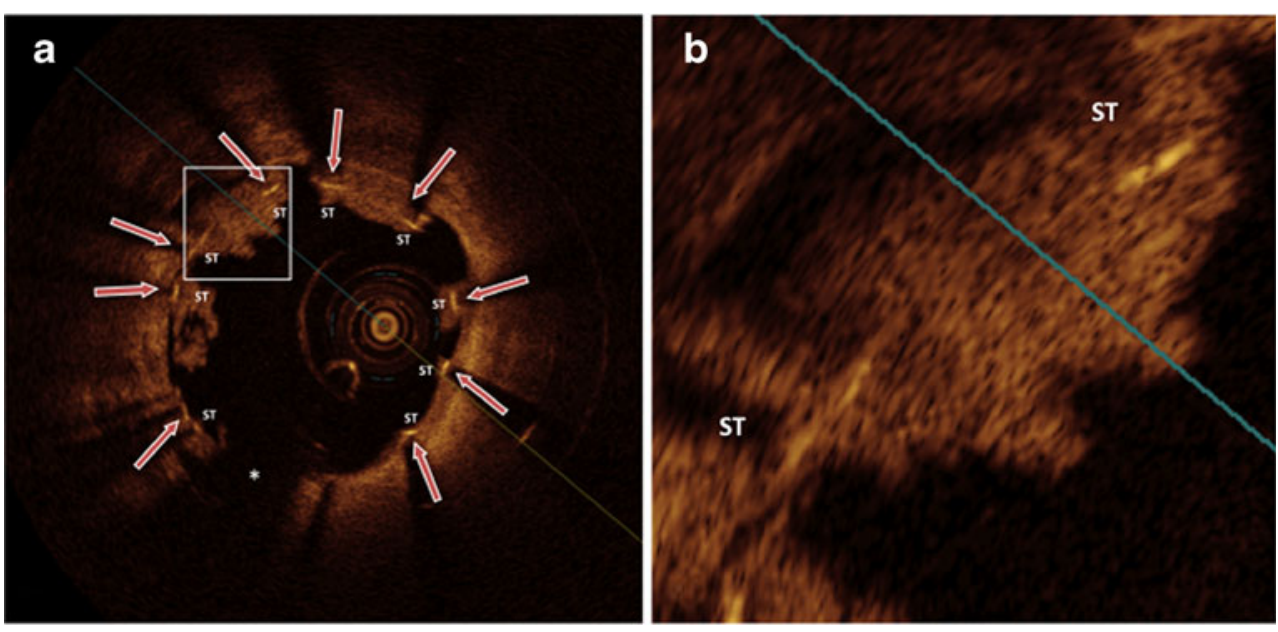

material vs stable coronary disease) likely also determine the degree and time-line of stent healing.

\section{Comparison of Stent Strut Coverage and Malapposition Between DES vs BMS, Different DES, or in Patients with Stable CAD vs an Acute Coronary Syndrome}

There have now been more than 30 observational or randomized studies reported using OCT to examine stent healing after coronary stent implantation, largely focusing on detection of the percentage of uncovered stent struts and stent struts with malapposition (for summary of randomized studies see Table 1), and some of these recent observations are described below.
OCT Studies Comparing DES vs BMS

The largest randomized study to date using OCT to compare the vascular response after implantation of a DES (TAXUS Express, paclitaxel-eluting stent) and an otherwise identical bare-metal stent (Express BMS) is the OCT substudy of the prospective, randomized Harmonizing Outcomes with $\mathrm{Re}$ vascularization and Stents in Acute Myocardial Infarction (HORIZONS-AMI) trial in patients with ST-segment elevation myocardial infarction (STEMI) that has included 118 consecutive randomized patients [18]. The TAXUS Express, paclitaxel-eluting stents (PESs) reduced neointimal hyperplasia, but had also a higher rate of uncovered and malapposed stent struts as compared with the otherwise identical BMS when examined 13 months after stent implantation

Table 1 Randomized trials using OCT for evaluation of stent strut coverage and malapposition

\begin{tabular}{llllll}
\hline Study & Stent type & $\mathrm{N}$ & $\begin{array}{l}\text { Follow-up } \\
\text { (months) }\end{array}$ & Uncovered stent struts (\%) & $\begin{array}{l}\text { Stent strut malapposition } \\
(\%)\end{array}$ \\
\hline DES vs BMS & & & & & \\
Guagliumi et al. [18] & PES vs BMS & 118 & 13 & 5.7 vs 1.1 & 0.9 vs 0.1 \\
Guagliumi et al. [19] & SES vs PES vs ZES vs BMS & 77 & 6 & 8.1 vs 4.1 vs 0.1 vs 0.9 & 2.3 vs 2.3 vs 0.0 vs 0.1 \\
Guagliumi et al. [20] & ZES vs BMS & 44 & 6 & 0.0 vs 2.0 & 0.0 vs 0.15 \\
DES vs DES & & & & 12.7 vs 6.6 & 1.4 vs 0.5 \\
Miyoshi et al. [52] & SES vs PES & 27 & 6 & 11.7 vs 2.8 & 2.2 vs 1.2 \\
Moore et al. [53] & Polymer-c. SES vs Non-pol. SES & 24 & 3 & 5.3 vs 7.0 & 1.4 vs 0.8 \\
Guagliumi et al. [54] & PES vs B-PES HD & 60 & 6 & 1.8 vs 6.3 & 0.1 vs 0.4 \\
Barlis et al. [22] & BES vs SES & 56 & 9 & 1.5 vs 1.8 & 1.8 vs 1.4 \\
Gutierrez-Chico [23] & BES vs SES & 21 & 24 & 7.4 vs 5.8 & 2.1 vs 5.7 \\
Gutierrez-Chico [24] & R-ZES vs EES & 58 & 13 & 2.3 vs 5.2 & 8.1 vs 5.3 \\
Takano et al. [25] & EES vs PES & 42 & 6 & & \\
DEB & & 26 & 6 & & \\
Gutierrez-Chico [55] & DCB+BMS vs BMS+DCB & 26.3 & \\
\hline
\end{tabular}

$B E S$ biolimus-eluting stent, $B M S$ bare-metal stent, $B-P E S$ biolimus-eluting stent with biodegradable polymer, $D C B$ drug-coated balloon, $E E S$ everolimus-eluting stent, $P E S$ paclitaxel-eluting stent, $P F-S E S$ polymer-free sirolimus-eluting stent, $R$-ZES zotarolimus-eluting stent with slowrelease and Biolynx polymer (Resolute), SES sirolimus-eluting stent, ZES zotarolimus-eluting stent (Endeavor) 
[18]. This phenomenon is observed for most drug-eluting stents, that suppress excessive neointima formation (i.e. restenosis), but also have a delayed stent strut healing. The fast-release zotarolimus-eluting stent (Endeavor) tested in the studies by Guagliumi et al. as shown in the DES vs BMS section of Table $1[19,20]$ had also a higher restenosis rate. In fact, the same authors have compared this stent with the later generation of zotarolimus-eluting, slow-release stents (Resolute), that more efficiently suppressed restenosis, and have observed a stronger suppression of the neointimal response but also a higher proportion of uncovered and malapposed stent struts at the 6-month OCT follow-up with the newer generation of the zotarolimus-eluting stents (Resolute) [21].

\section{OCT Studies Comparing Different DES}

Within the LEADERS trial an OCT substudy was performed in 56 patients to compare stent strut coverage following implantation of a biodegradable versus a durable polymer-coated drug-eluting stent [22]. Stent strut coverage at a mean followup of 9 months appeared to be more complete in patients after implantation of biodegradable polymer-coated, biolimuseluting stents (BESs) when compared with the durable polymer-coated sirolimus-eluting stents (SESs) [22]. A longterm follow-up OCT exam suggested that after 24 months the stent strut coverage was similar between the two stent types, i.e. $1.5 \%$ versus $1.8 \%$ uncovered stent struts [23].

An OCT substudy of the RESOLUTE All Comers trial has compared stent healing of the hydrophilic polymercoated zotarolimus-eluting stent (Resolute) with fluoropolymer-coated everolimus-eluting stent (Xience V) at 13-month follow-up [24]. There were no significant differences observed with respect to stent strut tissue coverage and malapposition at 13-month follow-up, e.g. $7.4 \%$ and $5.8 \%$ uncovered stent struts [24]. A recent prospective, randomized OCT study has compared coronary stent healing after everolimus-eluting stent (EES) and paclitaxel-eluting stent (PES) implantation and has suggested a favorable stent healing response after EES implantation in a 6 months follow-up examination (Table 1) [25]. Several studies using OCT to compare stent healing of different DES are summarized in Table 1, suggesting that besides the stent implantation technique and the clinical scenario the design of DES likely is important for the vascular healing response.

\section{OCT Examination After DES-Implantation in Stable CAD and Acute MI}

Retrospective pathological and clinical coronary OCT imaging studies have observed a higher rate of uncovered and malapposed stent struts in DES that were implanted during an acute STEMI as compared to DES implanted in patients with stable coronary disease [26-28], suggesting that the clinical situation where stent implantation is performed needs to be considered for the interpretation of the stent healing response. Figure 3 shows an OCT in a patient with NSTEMI before and after coronary stent implantation, where thrombotic material is to be seen under stent struts revealing one potential mechanism promoting malapposition in patients with an acute coronary syndrome (Fig. 3).

OCT Evaluation of New Stent Technologies, eg Bioengineered Stents

OCT is being used to examine whether novel stent technologies may have an accelerated or favorable vascular healing response. The above described data suggest that drugeluting stents that efficiently suppress restenosis have mostly some degree of delayed stent healing. Therefore there has been substantial interest in designing bioengineered stents with a potential to accelerate stent healing. The REMEDEE OCT study is currently randomizing 60 patients with an acute coronary syndrome to receive either a CD34+antibody covered, sirolimus-eluting stent (Genous Combo) or an everolimus-eluting stent (Xience V or Promus) and evaluates the early stent healing response by OCT/OFDI at 2 month follow-up (ClinicalTrials.gov Identifier: NCT01405287).

\section{OCT Imaging After Stent Implantation: Tissue Characterization Around Stent Struts}

While the resolution of OCT is substantially greater as compared to ultrasound and can be in the range of $10 \mu \mathrm{m}$ axial and $20-40 \mu \mathrm{m}$ lateral resolution, it does not allow detection of a single cell layer (such as the endothelium), that might become possible with the microOCT systems that have been examined in the experimental setting [29]. However, several studies have suggested a close relation between the detection of stent strut coverage by OCT as compared to histology $[30 \bullet, 31,32]$. Moreover, there has been substantial interest in OCT image characteristics that may aid in the distinction between different tissues covering stent struts, i.e. fibrin coverage with thrombotic material vs neointimal coverage. Backscattering intensity and signal attenuation may provide information for the further discrimination of stent strut coverage tissue type, in particular a lower OCT signal intensity has been observed for fibrin-covered stent struts as compared to neointimal covered stent struts [30•, 31]. In a study of porcine coronary stent implantation we have observed that fibrin-rich tissue as detected early after porcine coronary stent implantation and confirmed by electron microscopy had a substantially lower OCT signal-intensity when compared to neointima-covered stent struts later after implantation, that were covered by smooth muscle cell-rich 
Fig. 3 This image illustrates potential aspects of why an acute coronary syndrome may predispose to an impaired stent healing: a, Red thrombus in the culprit lesion of the proximal segment of RCX in a patient with NSTEMI; $\mathbf{b}$, After stent implantation stent struts with underlying and protruding thrombi are to be seen likely promoting malapposition (red arrows). Asterisk indicates OCT catheter

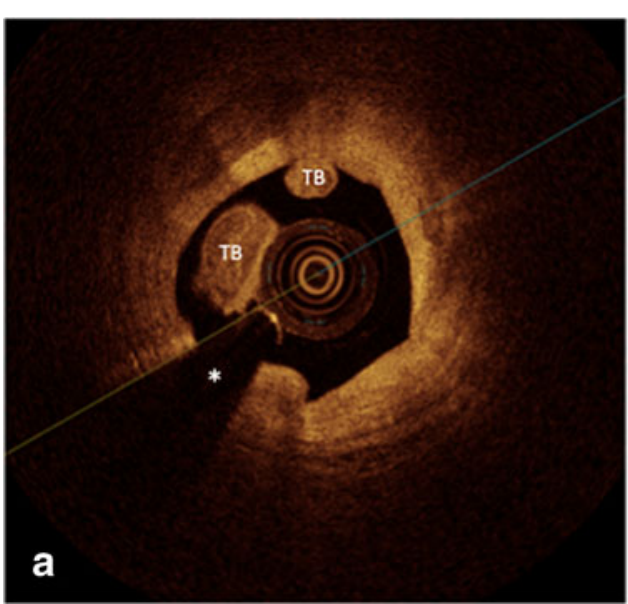

tissue with extracellular matrix containing collagens [30•]. Nakano et al. have recently reported in a study using stents obtained at autopsy that a lower signal intensity and a greater signal attenuation was observed for fibrin as compared to neointima-covered stent struts when examined by OFDI [31]. Furthermore, the luminal surface appears more irregular when stent struts are covered by fibrin accumulation as compared to neointima $[30 \bullet, 31]$. It is likely that the further characterization of the type of tissue coverage of the stent struts will be important, since only neointima, but not fibrincoverage of stent struts can be considered as an effective stent healing. For example, a recent study in patients with STEMI has reported an OCT follow-up after 3-7 days and reported a high percentage of stent struts that were covered with a thin rim, making it likely that this may rather represent fibrin than neointimal stent strut coverage [33].

\section{OCT: A Valuable Tool for Evaluation of Vascular Response of Bioabsorbable Stents}

The reproducibility of gray-scale IVUS was reported to be lower as compared with OCT for detection of qualitative findings after bioresorbable vascular scaffold (BVS) implantation [34]. OCT is capable of an accurate assessment of the polymeric struts, the changes in luminal and scaffold dimensions, and the quantification of neointimal hyperplasia [35••]. The amount of backscattering in OCT imaging depends on the material and the progress of strut biodegradation. Recently published studies have provided data with respect to safety and feasibility of bioresorbable stents as revealed by OCT $[35 \bullet \bullet, 36]$. Two years after bioabsorbable everolimus-eluting coronary stent implantation in the ABSORB study OCT imaging suggested that the stents had

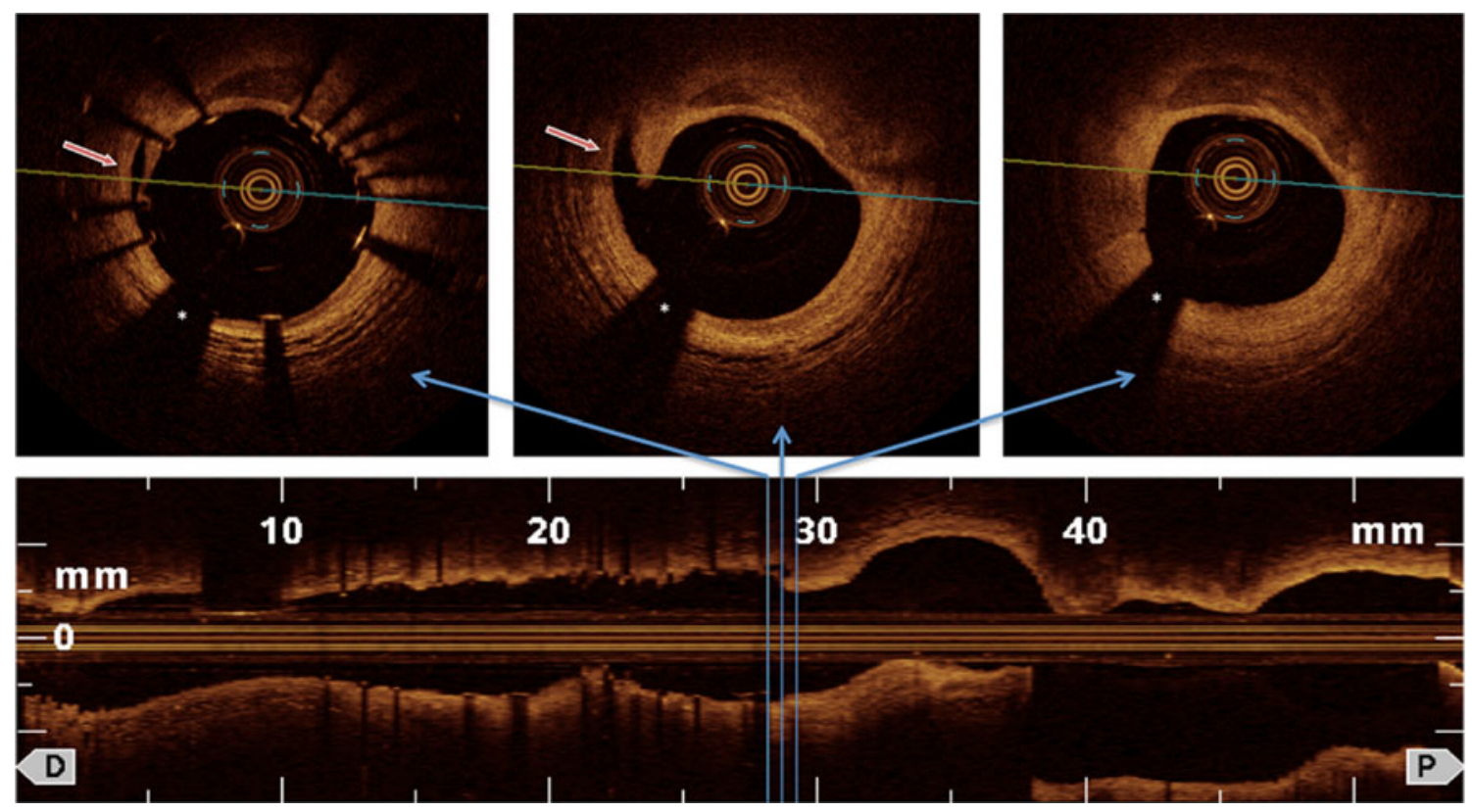

Fig. 4 In stent dissection and edge dissection after coronary stent implantation that can be detected by OCT and frequently would not be seen by angiography or IVUS (red arrows). Asterisk indicates OCT catheter 
been incorporated into the vessel wall and was largely bioabsorbed; $34 \%$ of the stent struts were no longer discernible at all by OCT after 2 years, suggesting that they had been completely bioabsorbed [35••]. The OCT/OFDI quantification of the healing process after bioabsorbable stent implantation has important differences as compared to the metalscaffold stents. Strut core areas do not produce dorsal shadows which allows for a complete imaging of strut thickness $[37,38]$.

\section{OCT Examination of Stent Healing and Risk of Stent Thrombosis}

Late and very late stent thrombosis is a rare, but feared complication after coronary stent implantation. Several causes can lead to late or very late stent thrombosis, including impaired stent healing (uncovered/malapposed stent struts), but also neoatherosclerosis and rupture within the stent $[8 \cdot, 39]$. As described above, autopsy studies have suggested that the percentage of uncovered stent struts is particularly high in patients who died from a stent thrombosis $[8 \bullet, 39]$. The clinical implications, however, of a certain percentage of uncovered or malapposed stent struts need to be further examined and evaluated. In this respect, a recent case-controlled study has suggested a substantially increased frequency and length of uncovered and malapposed stent struts as assessed by OCT in patients with late stent thrombosis after DES implantation (percentage of uncovered stent struts $12.2 \%$ vs. $4.1 \%$ ) [40॰]. In pathological studies the presence of $>30 \%$ uncovered stent-struts was highly predictive of in-stent thrombosis after DES implantation [8•]. Ozaki et al. reported, that incomplete stent apposition without neointimal hyperplasia was significantly associated with the presence of OCT-detected thrombus at follow-up, and may constitute a potent substrate for LIST [14].

Besides impaired stent healing, neoatherosclerosis may also contribute to clinical events late after DES implantation due to neointimal rupture as suggested by a recent study using OCT [41].

\section{OCT and Detection of Subclinical Dissections After Stent Implantation (Edge Dissections)}

Because of the high resolution of OCT small intimal dissections, also termed small intimal disruptions, are more frequently observed after coronary stent implantation by OCT as compared to what is detected by angiography or IVUS [42] (see example Fig. 4). Such subclinical dissections are detected within the stent, but often also at the stent edges (i.e. edge dissections) [43]. There is no evidence that such subclinical dissections as revealed by OCT should be "sealed" by additional overlapping stents [43]. On the contrary, multiple overlapping stents are known to be associated with stent strut malapposition and have been reported as a predictor of LIST after DES [44]. In a study analyzing the acute effects of coronary stenting by OCT in 80 vessels (and 73 patients), a stent edge dissection was detected in 20 vessels without clinical events during hospitalization [43]. A small study has reported the frequency of stent edge dissection as detected by OCT or IVUS during acute stent implantation and follow-up after approximately 6 months in 36 patients [45]. Notably, all OCT-detected stent edge dissections were healed without thrombus formation at the late follow-up [45], suggesting that small edge dissections should not prompt additional stent implantation.

A recent study using OCT, however, has suggested that intra-stent dissections (besides thin-cap fibroatheroma and intra-stent thrombus) were associated with a higher risk of periprocedural (type IVa) myocardial infarction in 50 patients with stable CAD or an NSTEMI [46].

\section{Future Perspectives/Conclusions}

OCT is a feasible and safe imaging modality for the detailed evaluation of the acute and chronic vascular response after coronary stent implantation, allowing detection of stent strut coverage, strut malapposition, angiographically inapparent thrombus formation, and small intimal ruptures [32, 47-50]. OCT reveals much more detail after coronary stent implantation as compared to IVUS [51]. A remaining challenge is to better define the clinical implications of the observations made by OCT, that will likely require larger OCT studies and registries with long-term follow-up.

Disclosure M. Jaguszewski: none; U. Landmesser: speakers' honoraria for oral presentations from Orbus \& Neich and Terumo.

Open Access This article is distributed under the terms of the Creative Commons Attribution License which permits any use, distribution, and reproduction in any medium, provided the original author(s) and the source are credited.

\section{References}

Papers of particular interest, published recently, have been highlighted as:

- Of importance,

•• Of major importance

1. Huang D, Swanson EA, Lin CP, et al. Optical coherence tomography. Science. 1991;254:1178-81. 
2. Suter MJ, Nadkarni SK, Weisz G, et al. Intravascular optical imaging technology for investigating the coronary artery. JACC Cardiovasc Imaging. 2011;4:1022-39.

3. Yun SH, Tearney GJ, Vakoc BJ, et al. Comprehensive volumetric optical microscopy in vivo. Nat Med. 2006;12:1429-33.

4. Takarada S, Imanishi T, Liu Y, et al. Advantage of next-generation frequency-domain optical coherence tomography compared with conventional time-domain system in the assessment of coronary lesion. Catheter Cardiovasc Interv. 2010;75:202-6.

5. Kataiwa H, Tanaka A, Kitabata H, et al. Head to head comparison between the conventional balloon occlusion method and the nonocclusion method for optical coherence tomography. Int J Cardiol. 2011;146:186-90.

6. Kotani J, Awata M, Nanto S, et al. Incomplete neointimal coverage of sirolimus-eluting stents: angioscopic findings. J Am Coll Cardiol. 2006;47:2108-11.

7. Daemen J, Wenaweser P, Tsuchida K, et al. Early and late coronary stent thrombosis of sirolimus-eluting and paclitaxel-eluting stents in routine clinical practice: data from a large two-institutional cohort study. Lancet. 2007;369:667-78.

8. - Finn AV, Joner M, Nakazawa G, et al. Pathological correlates of late drug-eluting stent thrombosis: strut coverage as a marker of endothelialization. Circulation 2007;115:2435-41. This paper describes the pathological findings in patients who died from late stent thrombosis.

9. Joner M, Finn AV, Farb A, et al. Pathology of drug-eluting stents in humans: delayed healing and late thrombotic risk. J Am Coll Cardiol. 2006;48:193-202.

10. Farb A, Burke AP, Kolodgie FD, et al. Pathological mechanisms of fatal late coronary stent thrombosis in humans. Circulation. 2003;108:1701-6.

11. Matsumoto D, Shite J, Shinke T, et al. Neointimal coverage of sirolimus-eluting stents at 6-month follow-up: evaluated by optical coherence tomography. Eur Heart J. 2007;28:961-7.

12. Cook S, Wenaweser $\mathrm{P}$, Togni $\mathrm{M}$, et al. Incomplete stent apposition and very late stent thrombosis after drug-eluting stent implantation. Circulation. 2007;115:2426-34.

13. Hassan AK, Bergheanu SC, Stijnen T, et al. Late stent malapposition risk is higher after drug-eluting stent compared with baremetal stent implantation and associates with late stent thrombosis. Eur Heart J. 2010;31:1172-80.

14. Ozaki Y, Okumura M, Ismail TF, et al. The fate of incomplete stent apposition with drug-eluting stents: an optical coherence tomographybased natural history study. Eur Heart J. 2010;31:1470-6.

15. • Tearney GJ, Regar E, Akasaka T, et al. Consensus standards for acquisition, measurement, and reporting of intravascular optical coherence tomography studies: a report from the international working group for intravascular optical coherence tomography standardization and validation. J Am Coll Cardiol 2012;59:105872. This paper descibes a standardization of OCT image analysis.

16. Gutierrez-Chico JL, Regar E, Nuesch E, et al. Delayed coverage in malapposed and side-branch struts with respect to well-apposed struts in drug-eluting stents: in vivo assessment with optical coherence tomography. Circulation. 2011;124:612-23.

17. Gutierrez-Chico JL, Wykrzykowska J, Nuesch E, et al. Vascular tissue reaction to acute malapposition in human coronary arteries: sequential assessment with optical coherence tomography. Circ Cardiovasc Interv. 2012;5(20-9):S1-8.

18. Guagliumi G, Costa MA, Sirbu V, et al. Strut coverage and late malapposition with paclitaxel-eluting stents compared with bare metal stents in acute myocardial infarction: optical coherence tomography substudy of the Harmonizing Outcomes with Revascularization and Stents in Acute Myocardial Infarction (HORIZONS-AMI) Trial. Circulation. 2011;123:274-81.

19. Guagliumi G, Musumeci G, Sirbu V, et al. Optical coherence tomography assessment of in vivo vascular response after implantation of overlapping bare-metal and drug-eluting stents. JACC Cardiovasc Interv. 2010;3:531-9.

20. Guagliumi G, Sirbu V, Bezerra H, et al. Strut coverage and vessel wall response to zotarolimus-eluting and bare-metal stents implanted in patients with ST-segment elevation myocardial infarction: the OCTAMI (Optical Coherence Tomography in Acute Myocardial Infarction) Study. JACC Cardiovasc Interv. 2010;3:680-7.

21. Guagliumi G, Ikejima H, Sirbu V, et al. Impact of drug release kinetics on vascular response to different zotarolimus-eluting stents implanted in patients with long coronary stenoses: the LongOCT study (Optical Coherence Tomography in Long Lesions). JACC Cardiovasc Interv. 2011;4:778-85.

22. Barlis P, Regar E, Serruys PW, et al. An optical coherence tomography study of a biodegradable vs. durable polymer-coated limus-eluting stent: a LEADERS trial sub-study. Eur Heart J. 2010;31:165-76.

23. Gutierrez-Chico JL, Juni P, Garcia-Garcia HM, et al. Long-term tissue coverage of a biodegradable polylactide polymer-coated biolimus-eluting stent: comparative sequential assessment with optical coherence tomography until complete resorption of the polymer. Am Heart J. 2011;162:922-31.

24. Gutierrez-Chico JL, van Geuns RJ, Regar E, et al. Tissue coverage of a hydrophilic polymer-coated zotarolimus-eluting stent vs. a fluoropolymer-coated everolimus-eluting stent at 13 -month follow-up: an optical coherence tomography substudy from the RESOLUTE All Comers trial. Eur Heart J. 2011;32:2454-63.

25. Takano M, Murakami D, Yamamoto M, et al. Six-month follow-up evaluation for everolimus-eluting stents by intracoronary optical coherence tomography: Comparison with paclitaxel-eluting stents. Int J Cardiol 2011.

26. Nakazawa G, Finn AV, Joner M, et al. Delayed arterial healing and increased late stent thrombosis at culprit sites after drug-eluting stent placement for acute myocardial infarction patients: an autopsy study. Circulation. 2008;118:1138-45.

27. Gonzalo N, Barlis P, Serruys PW, et al. Incomplete stent apposition and delayed tissue coverage are more frequent in drug-eluting stents implanted during primary percutaneous coronary intervention for STsegment elevation myocardial infarction than in drug-eluting stents implanted for stable/unstable angina: insights from optical coherence tomography. JACC Cardiovasc Interv. 2009;2:445-52.

28. Kubo T, Imanishi T, Kitabata H, et al. Comparison of vascular response after sirolimus-eluting stent implantation between patients with unstable and stable angina pectoris: a serial optical coherence tomography study. JACC Cardiovasc Imaging. 2008;1:475-84.

29. Liu L, Gardecki JA, Nadkarni SK, et al. Imaging the subcellular structure of human coronary atherosclerosis using micro-optical coherence tomography. Nat Med. 2011;17:1010-4.

30. - Templin C, Meyer M, Muller MF, et al. Coronary optical frequency domain imaging (OFDI) for in vivo evaluation of stent healing: comparison with light and electron microscopy. Eur Heart $J$ 2010;31:1792-801. This paper describes differences in OCT image characteristics for different tissue types covering coronary stent struts.

31. Nakano M, Vorpahl M, Otsuka F, et al. Ex vivo assessment of vascular response to coronary stents by optical frequency domain imaging. JACC Cardiovasc Imaging. 2012;5:71-82.

32. Murata A, Wallace-Bradley D, Tellez A, et al. Accuracy of optical coherence tomography in the evaluation of neointimal coverage after stent implantation. JACC Cardiovasc Imaging. 2010;3:76-84.

33. Prati F, Stazi F, Dutary J, et al. Detection of very early stent healing after primary angioplasty: an optical coherence tomographic observational study of chromium cobaltum and first-generation drugeluting stents. The DETECTIVE study Heart. 2011;97:1841-6.

34. Gomez-Lara J, Brugaletta S, Diletti R. et al. Catheter Cardiovasc Interv: Agreement and reproducibility of gray-scale intravascular ultrasound and optical coherence tomography for the analysis of the bioresorbable vascular scaffold; 2011. 
35. •- Serruys PW, Ormiston JA, Onuma Y, et al. A bioabsorbable everolimus-eluting coronary stent system (ABSORB): 2-year outcomes and results from multiple imaging methods. Lancet 2009;373:897-910. This paper describes the OCT follow-up of a bioabsorbable stent.

36. Brugaletta S, Radu MD, Garcia-Garcia HM, et al. Circumferential evaluation of the neointima by optical coherence tomography after ABSORB bioresorbable vascular scaffold implantation: can the scaffold cap the plaque? Atherosclerosis. 2012;221:106-12.

37. Serruys PW, Onuma Y, Ormiston JA, et al. Evaluation of the second generation of a bioresorbable everolimus drug-eluting vascular scaffold for treatment of de novo coronary artery stenosis: six-month clinical and imaging outcomes. Circulation. 2010;122:2301-12.

38. Serruys PW, Onuma Y, Dudek D, et al. Evaluation of the second generation of a bioresorbable everolimus-eluting vascular scaffold for the treatment of de novo coronary artery stenosis: 12-month clinical and imaging outcomes. J Am Coll Cardiol. 2011;58:157888 .

39. Ikenaga $H$, Ishihara $M$, Dai K, et al. Mechanisms of very late stent thrombosis after drug-eluting stent implantation: findings from coronary angioscopy and optical coherence tomography. JACC Cardiovasc Imaging. 2011;4:1217-9.

40. - Guagliumi G, Sirbu V, Musumeci G, et al. Examination of the in vivo mechanisms of late drug-eluting stent thrombosis: findings from optical coherence tomography and intravascular ultrasound imaging. JACC Cardiovasc Interv 2012;5:12-20. This paper describes OCT findings in patients with late stent thrombosis.

41. Kang SJ, Mintz GS, Akasaka T, et al. Optical coherence tomographic analysis of in-stent neoatherosclerosis after drug-eluting stent implantation. Circulation. 2011;123:2954-63.

42. Gonzalo N, Serruys PW, Okamura T, et al. Relation between plaque type and dissections at the edges after stent implantation: an optical coherence tomography study. Int J Cardiol. 2011;150:151-5.

43. Gonzalo N, Serruys PW, Okamura T, et al. Optical coherence tomography assessment of the acute effects of stent implantation on the vessel wall: a systematic quantitative approach. Heart. 2009;95:1913-9.

44. Tanigawa J, Barlis P, Dimopoulos K, et al. Optical coherence tomography to assess malapposition in overlapping drug-eluting stents. EuroIntervention. 2008;3:580-3.
45. Kume T, Okura H, Miyamoto Y, et al. Natural history of stent edge dissection, tissue protrusion and incomplete stent apposition detectable only on optical coherence tomography after stent implantation. Circ J. 2012;76:698-703.

46. Porto I, Di Vito L, Burzotta F, et al. Predictors of periprocedural (type IVa) myocardial infarction, as assessed by frequency-domain optical coherence tomography. Circ Cardiovasc Interv. 2012;5(89-96):S1-6.

47. Prati F, Regar E, Mintz GS, et al. Expert review document on methodology, terminology, and clinical applications of optical coherence tomography: physical principles, methodology of image acquisition, and clinical application for assessment of coronary arteries and atherosclerosis. Eur Heart J. 2010;31:401-15.

48. Capodanno D, Prati F, Pawlowsky T, et al. Comparison of optical coherence tomography and intravascular ultrasound for the assessment of in-stent tissue coverage after stent implantation. EuroIntervention. 2009;5:538-43.

49. Yonetsu T, Kakuta T, Lee T, et al. In vivo critical fibrous cap thickness for rupture-prone coronary plaques assessed by optical coherence tomography. Eur Heart J. 2011;32:1251-9.

50. Kume T, Okura H, Kawamoto T, et al. Assessment of the coronary calcification by optical coherence tomography. EuroIntervention. 2011;6:768-72.

51. Jang IK. Optical coherence tomography or intravascular ultrasound? JACC Cardiovasc Interv. 2011;4:492-4.

52. Miyoshi N, Shite J, Shinke T, et al. Comparison by optical coherence tomography of paclitaxel-eluting stents with sirolimus-eluting stents implanted in one coronary artery in one procedure.-6month follow-up. Circ J. 2010;74:903-8.

53. Moore P, Barlis P, Spiro J, et al. A randomized optical coherence tomography study of coronary stent strut coverage and luminal protrusion with rapamycin-eluting stents. JACC Cardiovasc Interv. 2009;2:437-44.

54. Guagliumi G, Sirbu V, Musumeci G, et al. Strut coverage and vessel wall response to a new-generation paclitaxel-eluting stent with an ultrathin biodegradable abluminal polymer: Optical Coherence Tomography Drug-Eluting Stent Investigation (OCTDESI). Circ Cardiovasc Interv. 2010;3:367-75.

55. Gutierrez-Chico JL, van Geuns RJ, Koch KT, et al. Paclitaxelcoated balloon in combination with bare metal stent for treatment of de novo coronary lesions: an optical coherence tomography first-in-human randomised trial, balloon first vs. stent first. EuroIntervention 2011;7:711-22. 